\title{
Haptoglobin Gene Polymorphism among Sickle Cell Patients in West Cameroon: Hematological and Clinical Implications
}

\author{
Christian Bernard Kengne Fotsing $\mathbb{D}^{1,2}$ Constant Anatole Pieme, ${ }^{3}$ \\ Prosper Cabral Biapa Nya ${ }^{D},{ }^{2}$ Jean Paul Chedjou, ${ }^{4}$ Samuel Ashusong, ${ }^{5}$ Gisele Njindam, \\ Jocelyn Tony Nengom, ${ }^{5}$ Georges Teto, ${ }^{6}$ Carine Nguemeni, ${ }^{7}$ Wilfred Fon Mbacham, ${ }^{4}$ \\ and Donatien Gatsing ${ }^{1}$
}

${ }^{1}$ Research Unit of Microbiology and Antimicrobial Substances, Department of Biochemistry, Faculty of Science, University of Dschang, P O. Box 67, Dschang, Cameroon

${ }^{2}$ Research Unit of Biochemistry of Medicinal Plants, Food Sciences and Nutrition, Department of Biochemistry, Faculty of Science, University of Dschang, P O. Box 67, Dschang, Cameroon

${ }^{3}$ Laboratory of Biochemistry, Department of Biochemistry and Physiological Sciences, Faculty of Medicine and Biomedical Sciences, University of Yaounde I, P O. Box, Yaounde 1364, Cameroon

${ }^{4}$ Laboratory for Public Health Research Biotechnology, Department of Biochemistry, University of Yaounde I, Yaounde, Cameroon

${ }^{5}$ Bafoussam Regional Hospital, P O. Box 980, Bafoussam, Cameroon

${ }^{6}$ Centre International de Recherche Chantal Biya, Yaounde, Cameroon

${ }^{7}$ Department of Neurology, University Hospital of Würzburg, Würzburg, Germany

Correspondence should be addressed to Prosper Cabral Biapa Nya; prbiapa@yahoo.fr

Received 25 May 2021; Accepted 7 October 2021; Published 20 October 2021

Academic Editor: Bashir A. Lwaleed

Copyright ( $(2021$ Christian Bernard Kengne Fotsing et al. This is an open access article distributed under the Creative Commons Attribution License, which permits unrestricted use, distribution, and reproduction in any medium, provided the original work is properly cited.

Haptoglobin is a protein involved in protecting the body from the harmful effects of free hemoglobin. The haptoglobin gene exhibits a polymorphism, and the different genotypes do not have the same capacity to combat the free hemoglobin effects. The present study aimed at determining the polymorphic distribution of haptoglobin in sickle cell patients (SCPs) from West Cameroon and their impact on the hematological parameters, as well as clinical manifestations of the disease severity. Haptoglobin genotype of 102 SCPs (SS) and 115 healthy individuals (60 AA and 55 AS) was determined by allele-specific polymerase chain reaction, and the complete blood count was determined using the AutoAnalyser. Results showed that the genotype Hp2-2 was significantly $(p<0.05)$ represented in SS patients $(54 \%)$ than in controls AA and AS ( $27 \%$ and $29 \%$, respectively), while Hp2-1 was mostly found $(p<0.05)$ in AS $(42 \%)$ and AA $(38 \%)$, against $15 \%$ in SS. The allelic distribution in SS patients was $\mathrm{Hp}^{2}: 0.613$, $\mathrm{Hp}^{1 \mathrm{~S}}: 0.304$, and $\mathrm{Hp}^{1 \mathrm{~F}}: 0.084$. In AA and AS controls, the proportions of the $\mathrm{Hp}^{1}$ and $\mathrm{Hp}^{2}$ alleles were similar (around 0.5 each),

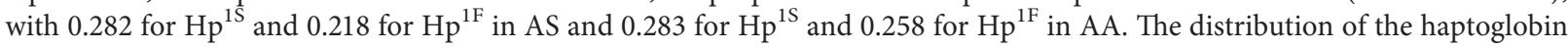
genotypes did not reveal any significant difference across hematological parameters and clinical manifestations of disease severity in SCP and controls. SCP with Hp1S-1F genotype presented the highest level of hemoglobin. Although Hp2-2 was more frequent in SS patients, it appeared not to be related to the hematological parameters and to the disease's severity. Further investigations are necessary to explore the impact of $\mathrm{Hp}$ polymorphism such as antioxidant, lipid profile, and functionality of some tissues in SCP in Cameroon. 


\section{Introduction}

Sickle cell disease (SCD) is the most common genetic disease in the world, affecting more than 50 million people, including 38 million in sub-Saharan Africa [1]. In Cameroon, the prevalence of the sickle cell trait (heterozygous AS) is estimated between 8 and 34\% [2], while the prevalence of the disease is between 2 and 3\% [3]. The disease kills about 4,000 people each year, all age groups are affected, and young people aged 10 to 29 years represent $89.2 \%$ of patients. This makes SCD a real public health problem. SCD is caused by a mutation at the 6 th codon of the beta chain of chromosome 11 , which results at the protein level in the substitution of glutamic acid by valine [4]. This substitution transforms hemoglobin A (HbA) into hemoglobin S (HbS) which polymerizes under hypoxia. The polymerization of $\mathrm{HbS}$ is at the centre of the pathophysiological process of sickle cell anemia (SCA), which is characterized mainly by chronic hemolytic anemia, vaso-occlusive crisis (VOC), and bacterial infections [5]. Chronic hemolysis results in the presence of a large amount of free hemoglobin in the blood, which is linked to increased endothelial adhesion and nitric oxide (NO) depletion $[6,7]$, leading to a decrease of its vasodilator, antithrombotic, and anti-inflammatory properties $[8,9]$. The first line of cleaning free hemoglobin in the blood is a protein called haptoglobin (Hp) $[7,10]$, which binds directly to free hemoglobin to form a very stable complex haptoglobinhemoglobin $(\mathrm{Hp}-\mathrm{Hb})$, eliminated by macrophages via phagocytosis $[6,10]$.

Haptoglobin is a $\alpha 2$-sialoglycoprotein synthesized by hepatocytes [11]. Its role is to bind the hemoglobin released during hemolytic episodes [12], thus protecting the body from the harmful effects of free hemoglobin. It also has antioxidant, bacteriostatic, NO inhibition, and prostaglandin synthesis properties. Its angiogenic effects are necessary for the proliferation and differentiation of endothelial cells during angiogenesis [13]. This protein is present in all mammals, but its polymorphism has only been reported in humans [6]. Molecular variations in Hp were first suspected by Jayle and Judas in 1946 [14]. In 1955, Smithies [15] identified three phenotypes of haptoglobin, Hp1-1, Hp2-1, and Hp2-2. Smithies and Walker [16] have shown that these phenotypes are controlled by two autosomal alleles $\mathrm{Hp}^{1}$ and $\mathrm{Hp}^{2}$, located on chromosome 16, locus 22. Later, Connell et al. [17] and Smithies et al. [18] showed that Hp1 can be divided into two subtypes, $\mathrm{Hp} 1 \mathrm{~S}$ and $\mathrm{Hp} 1 \mathrm{~F}$, thus giving rise to a total of 6 different genotypes (Hp1S-1S, Hp1F-1S, Hp1F1F, Hp2 -1S, Hp2-1F, and Hp2-2) [19].

These different genotypes have different potentials to counter the effects of free hemoglobin in blood [10]. For example, Hp1-1 is biologically more active than others in binding hemoglobin and suppressing its inflammatory effects $[13,20]$. Likewise, Melamed-Frank et al. [21] established that patients with Hp2-2 are more prone to oxidative stress than others. Various clinical conditions have been associated with the polymorphism of haptoglobin. Roguin et al. [22] showed that Hp2-2 is associated with myocardial infarction, as a predictor of the severity and extent of infarction damage in patients with different risk factors. Regarding SCD, Ostrowski et al. [23] as well as Moreira and Naoum [24] already reported a strong association between the disease and the Hp1-1 genotype. Other works have suggested that haptoglobin polymorphism may be involved in the pathophysiology of SCA $[6,25]$. In 2014, Gueye et al. [26] conducted studies whose results suggest that SS patients with $\mathrm{Hp} 2-2$ genotype exhibited significantly lower $\mathrm{Hb}$ means compared to $\mathrm{Hp} 1-1$ and $\mathrm{Hp} 2-1$ subjects. More recently, Chintagari et al. [27] in an in vitro study in sickle cell mice showed that $\mathrm{Hp}$ attenuates the toxic effects of hem and iron released after hemolysis. Several preclinical studies are underway to determine how haptoglobin can be used as a specific modulator in SCD and to assess its possible side effects.

It is recognized that the prevalence of different $\mathrm{Hp}$ genotypes may vary depending on several factors including geographic area and ethnicity [28-30]. A good knowledge of $\mathrm{Hp}$ and its polymorphic distribution could help in the fight against SCD. However, to our best knowledge, there are no data on the polymorphism of haptoglobin in sickle cell patients (SCP) in Cameroon. The objective of the present study was, therefore, to determine the polymorphic distribution of haptoglobin genes in SCP from West Cameroon and to evaluate their impact on some hematological parameters in SCP.

\section{Materials and Methods}

2.1. Study Design and Subjects. This was a cross-sectional descriptive study conducted at the West Regional Hospital located in Bafoussam (RHB), Cameroon, from September 2018 to November 2019. One hundred and two (102) SS patients (aged 1 to 40 years) regularly in consultation in RHB were recruited for this study. Patients with other pathologies, pregnant women, patients receiving investigational drugs, patients under blood transfusion, and patients with the past three months' history of crisis were not included in the study. In addition, fifty-five (55) subjects with sickle cell trait (AS) and sixty (60) healthy individuals (AA) as controls were included. They were selected in the west region like SS patients, and they were not genetically related to the patients. SS, AS, and AA phenotypes were determined by agarose gel electrophoresis using the kit CELLOGEL. All the participants were informed of the objectives of the study and were requested written informed consent (of their parents or legal guardians) according to the Declaration of Helsinki. The study was approved by the Ethics Review and Consultancy Committee (ERCC) of CAMBIN (Cameroon Bioethics Initiative) with the reference no: CBI/424/ERCC/CAMBIN.

\subsection{Methods}

2.2.1. Sample Collection and Hematological Parameter Measurement. Five millilitres of blood was collected in EDTA tubes and spotted on filter paper for molecular analyses. Complete blood count was carried out immediately after their collection, using the Mindray BC-2800 AutoAnalyser, and semiquantitative immunometric assay of C-reactive protein (CRP) was evaluated by latex agglutination using the DIALAB kit. 
2.2.2. DNA Extraction and Haptoglobin Genotyping. DNA was extracted from dried blood spots heated at $100^{\circ} \mathrm{C}$ in Chelex-100 in buffered Tris-EDTA as previously described by Plowe et al. [31]. Blood spots on the filter paper were excised with a sterile pair of surgical scissors. The DNA was stored in Tris-EDTA buffer at $-20^{\circ} \mathrm{C}$ until $\mathrm{Hp}$ genotyping was performed. Hp genotyping was performed by allele-specific PCR as previously described by Yano et al. [19]. PCR was performed in a $25 \mu \mathrm{L}$ reaction mixture consisting of $10 \mathrm{mM}$ Tris- $\mathrm{HCl}(\mathrm{pH} 9.0), 50 \mathrm{mM} \mathrm{KCl}, 0.1 \%$ Triton X-100, $2.5 \mathrm{mM} \mathrm{MgCl}_{2}, 200 \mu \mathrm{M}$ of each dNTP, $1.5 \mathrm{U}$ of Taq DNA polymerase, and $0.2 \mu \mathrm{M}$ of each primer with $1 \mu \mathrm{L}$ of DNA extract. Cycling conditions were as follows: $95^{\circ} \mathrm{C}$ for $3 \mathrm{~min}$, followed by 35 cycles of $94^{\circ} \mathrm{C}$ for $40 \mathrm{sec}, 58^{\circ} \mathrm{C}$ for $1 \mathrm{~min}$, and $72^{\circ} \mathrm{C}$ for $2 \mathrm{~min}$. Final extension was carried out at $72^{\circ} \mathrm{C}$ for $5 \mathrm{~min}$, after which PCR products were stored at $4^{\circ} \mathrm{C}$ for immediate use or $-20^{\circ} \mathrm{C}$ for long-term use. The $\mathrm{T} 3$ thermal cycler (Biometra, UK) was used for the PCR amplification. PCR products were electrophoresed at $50 \mathrm{~V}$ for $1 \mathrm{~h}$ on $1.2 \%$ agarose gels and stained with ethidium bromide, and the Hp genotypes were determined by observing the DNA fragments under UV light. Table 1 shows the sequences of primers, and Table 2 shows the combinations of the primers and predicted sizes of DNA fragments amplified in each reaction.

\section{Data Analyses}

Data were analysed using Statistical Package for the Social Sciences 20 (SPSS, IBM). The frequencies of the genotypes and individual alleles are presented as percentages. Comparisons were made within and between groups using the chi-square test associated with the $z$-test (Bonferroni adjustment) and one-way ANOVA. According to the size of a population group which was above thirty as well as the descriptive explored test of Levene, statistical tests for parametric tests were used. The significant difference was considered at $p<0.05$.

\section{Results}

Table 3 shows the distribution of the study population according to age and sex. The sex ratio $(\mathrm{M} / \mathrm{F})$ and the mean age of SS patients are 1.04 and 9.5 years, respectively.

The hematological parameters of the different group populations are shown in Table 4 . SS patients present significantly low levels of hemoglobin, red blood cells, and hematocrit and significantly high levels of white blood cells, lymphocytes, monocytes, granulocytes, and platelets compared to AS and AA.

Haptoglobin genotype and allele frequency distribution in the study population are shown in Table 5. Out of 217 participants, the most common $\mathrm{Hp}$ genotype was $\mathrm{Hp} 2-2$ (40\%). Among those carrying the $\mathrm{Hp}^{1}$ allele, the frequencies were $19.4 \%, 17.1 \%, 11.1 \%, 9.7 \%$, and $2.8 \%$, respectively, for Hp1S-1S, Hp2-1S, Hp2-1F, Hp1F-1F, and 1S-1F, which gave the following allelic distribution: $\mathrm{Hp}^{2}: 0.541, \mathrm{Hp}^{1 \mathrm{~S}}: 0.293$, and $\mathrm{Hp}^{1 \mathrm{~F}}: 0.166$. According to the $\mathrm{chi}^{2}$ test associated with Bonferroni adjustment, the Hp2-2 genotype was
TABle 1: Nucleotide sequences of the primers used.

\begin{tabular}{lc}
\hline Primer & Oligonucleotide sequence $\left(5^{\prime}-3^{\prime}\right)$ \\
\hline F3 & CAGGAGTATACACCTTAAATG \\
S2 & TTATCCACTGCTTCTCATTG \\
C42 & TTACACTGGTAGCGAACCGA \\
C72 & AATTTAAAATTGGCATTTCGCC \\
C51 & GCAATGATGTCACGGATATC \\
\hline
\end{tabular}

TABle 2: Primer set for PCR.

\begin{tabular}{lccc}
\hline Reaction & Primer sets (F-R) & Target alleles & Predicted size (bp) \\
\hline Reaction 2 & F3-C42 & $\mathrm{Hp}^{2}$ & 935 \\
Reaction S & C51-S2 & $\mathrm{Hp}^{1 \mathrm{~S}}$ & 1200 \\
Reaction F & F3-C72 & $\mathrm{Hp}^{1 \mathrm{~F}}$ & 1400 \\
\hline
\end{tabular}

TABLe 3: Age and sex distribution of the study population.

\begin{tabular}{lcccc}
\hline Variables & & SS $(n=102)$ & AS $(n=55)$ & AA $(n=60)$ \\
\hline \multirow{2}{*}{ Gender } & Male & $52(51 \%)$ & $10(18.2 \%)$ & $28(46.7 \%)$ \\
Sex ratio & Female & $50(49 \%)$ & $45(81.8 \%)$ & $32(43.3 \%)$ \\
$(\mathrm{M} / \mathrm{F})$ & & 1.04 & 0.22 & 0.88 \\
Age (years) & $\begin{array}{c}\text { Mean } \pm \text { SD } \\
\text { Range }\end{array}$ & $9.5 \pm 7.1$ & $25.1 \pm 16$ & $14.6 \pm 7.2$ \\
& & $1-40$ & $2-55$ & $1-36$ \\
\hline
\end{tabular}

SD: standard deviation.

significantly more represented in SS patients $(54 \%, p<0.01)$ than in controls AA (27\%) and AS (29\%), while Hp2-1 was mostly found significantly in AS $(42 \%, p<0.001)$ and AA $(38 \%, p<0.001)$, respectively, than in SS $(15 \%)$. Regarding intragroup $\mathrm{Hp}$ allele frequency distribution, $\mathrm{Hp}^{2}$ was the most present allele in SS with a proportion of 0.61 . We found a proportion of $\mathrm{Hp}^{1}$ of 0.38 in the same group (with 0.30 for $\mathrm{Hp}^{1 \mathrm{~S}}$ and only 0.08 for $\mathrm{Hp}^{1 \mathrm{~F}}$ ), while the proportions of the $\mathrm{Hp}^{1}$ and $\mathrm{Hp}^{2}$ alleles in AA and AS controls were similar (around 0.5 each) (Table 5).

The analysis of the variations of hematological parameters according to the Hp genotype in SS patients showed no significant difference in SCP (Table 6). Despite the nonsignificance, SCPs with the Hp1S-1F genotype presented the highest level of hemoglobin.

We analysed the variations of clinical manifestations of the severity of SCD (VOC occurrence, number of hospitalizations, sanguine transfusion, severity of anemia, CRP, and body mass index (BMI)) according to the Hp genotype in SS patients (Table 7). We found no significant difference between the different $\mathrm{Hp}$ genotypes in relation to these indicators of the severity of the disease in SCP $(p>0.05)$ for all indicators.

\section{Discussion}

The results of this study show that the sex ratio $(\mathrm{M} / \mathrm{F})$ is 1.04 in the SS group underlining that SCD distribution is independent of sex. Indeed, SCD is a genetic disease with recessive autosomic transmission; therefore, there is no distinction between men and women. The majority of patients were young (mean age: 9.5 years) with $90.23 \%$ of SCP 
TABLE 4: Hematological parameters among the study groups.

\begin{tabular}{|c|c|c|c|c|}
\hline Group & SS & AS & AA & $p$ value \\
\hline WBC $\left(\times 10^{9} / \mathrm{L}\right)$ & $18.06 \pm 8.45^{\mathrm{a}}$ & $7.55 \pm 3.96^{\mathrm{b}}$ & $6.19 \pm 1.81^{b}$ & $\leq 0.001^{*}$ \\
\hline Lymph $\left(\times 10^{9} / \mathrm{L}\right)$ & $8.38 \pm 4.68^{\mathrm{a}}$ & $3.50 \pm 2.29^{\mathrm{b}}$ & $2.85 \pm 0.94^{\mathrm{b}}$ & $\leq 0.001^{*}$ \\
\hline Mon $\left(\times 10^{9} / \mathrm{L}\right)$ & $1.89 \pm 0.85^{\mathrm{a}}$ & $0.78 \pm 0.52^{\mathrm{b}}$ & $0.57 \pm 0.21^{c}$ & $\leq 0.001^{*}$ \\
\hline Gran $\left(\times 10^{9} / \mathrm{L}\right)$ & $7.79 \pm 5.23^{\mathrm{a}}$ & $3.26 \pm 1.57^{\mathrm{b}}$ & $2.77 \pm 1.04^{\mathrm{b}}$ & $\leq 0.001^{*}$ \\
\hline Lymph\% & $46.2 \pm 10.5^{\mathrm{a}}$ & $45.5 \pm 8.6^{\mathrm{a}}$ & $46.3 \pm 8.4^{\mathrm{a}}$ & 0.880 \\
\hline Mon $\%$ & $10.9 \pm 3.5^{\mathrm{a}}$ & $10.4 \pm 3.2^{\mathrm{a}, \mathrm{b}}$ & $9.3 \pm 2.3^{\mathrm{b}}$ & $\leq 0.005^{*}$ \\
\hline Gran $\%$ & $42.8 \pm 10.8^{\mathrm{a}}$ & $44.0 \pm 8.6^{\mathrm{a}}$ & $44.4 \pm 8.6^{\mathrm{a}}$ & 0.523 \\
\hline $\mathrm{Hb}(\mathrm{g} / \mathrm{dL})$ & $7.49 \pm 1.32^{\mathrm{c}}$ & $11.66 \pm 2.03^{b}$ & $12.5 \pm 1.10^{\mathrm{a}}$ & $\leq 0.001^{*}$ \\
\hline $\mathrm{RBC}\left(\times 10^{12} / \mathrm{L}\right)$ & $2.98 \pm 0.68^{\mathrm{c}}$ & $4.77 \pm 0.84^{\mathrm{b}}$ & $5.08 \pm 0.43^{\mathrm{a}}$ & $\leq 0.001^{*}$ \\
\hline HCT $(\%)$ & $27.0 \pm 5.0^{c}$ & $40.5 \pm 6.6^{\mathrm{b}}$ & $43.0 \pm 3.36^{\mathrm{a}}$ & $\leq 0.001^{*}$ \\
\hline MCV (fL) & $91.1 \pm 12.8^{\mathrm{a}}$ & $85.7 \pm 8.1^{\mathrm{b}}$ & $85.0 \pm 5.6^{\mathrm{b}}$ & $\leq 0.001^{*}$ \\
\hline $\mathrm{MCH}(\mathrm{pg})$ & $25.64 \pm 3.05^{\mathrm{a}}$ & $24.55 \pm 2.32^{\mathrm{b}}$ & $24.46 \pm 2.17^{\mathrm{b}}$ & $\leq 0.001^{*}$ \\
\hline $\mathrm{MCHC}(\mathrm{g} / \mathrm{dL})$ & $27.91 \pm 1.50^{\mathrm{b}}$ & $28.69 \pm 0.86^{\mathrm{a}}$ & $28.99 \pm 0.72^{\mathrm{a}}$ & $\leq 0.001^{*}$ \\
\hline RDW-CV\% & $23.4 \pm 3.4^{\mathrm{a}}$ & $16.2 \pm 3.9^{\mathrm{b}}$ & $14.3 \pm 1.2^{\mathrm{c}}$ & $\leq 0.001^{*}$ \\
\hline RDW-SD (fL) & $76.5 \pm 13.4$ & $50.5 \pm 11.9$ & $45.7 \pm 4.3$ & $\leq 0.001^{*}$ \\
\hline $\operatorname{PLT}\left(\times 10^{9} / \mathrm{L}\right)$ & $469 \pm 181^{\mathrm{a}}$ & $333 \pm 150^{\mathrm{b}}$ & $283 \pm 78^{\mathrm{b}}$ & $\leq 0.001^{*}$ \\
\hline MPV (fL) & $9.83 \pm 0.67^{\mathrm{b}}$ & $10.14 \pm 0.66^{\mathrm{a}}$ & $10.05 \pm 0.84^{\mathrm{a}, \mathrm{b}}$ & $\leq 0.05^{*}$ \\
\hline PDW & $14.7 \pm 0.3$ & $14.5 \pm 0.2$ & $14.6 \pm 0.2$ & 0.175 \\
\hline РСТ\% & $7.51 \pm 0.9$ & $0.31 \pm 0.09$ & $0.28 \pm 0.07$ & 0.522 \\
\hline
\end{tabular}

WBC: white blood cells; RDW: red cell distribution width; PDW: platelet distribution width; PCT: platelet crit; a, $b$, and $c$ : values with different letters in the same line are significantly different at $p<0.05$; ANOVA with post hoc Dunnet T3.

TABle 5: Haptoglobin genotype and allele frequency distribution in the study population.

\begin{tabular}{|c|c|c|c|c|c|}
\hline Groups & & SS $(n=102)$ & AS $(n=55)$ & $\mathrm{AA}(n=60)$ & $p$ value \\
\hline \multirow{9}{*}{ Hp genotypes } & Hp 1-1 & $32(31.4 \%)^{\mathrm{a}}$ & $16(29.1 \%)^{\mathrm{a}, \mathrm{b}}$ & $21(35 \%)^{\mathrm{a}, \mathrm{b}}$ & $\leq 0.001^{*}$ \\
\hline & Hp 2-1 & $15(14.7 \%)^{\mathrm{b}}$ & $23(41.8 \%)^{\mathrm{a}}$ & $23(38.3 \%)^{\mathrm{a}}$ & \\
\hline & Hp 2-2 & $55(53.9 \%)^{\mathrm{a}}$ & $16(29.1 \%)^{b}$ & $16(26.7 \%)^{b}$ & \\
\hline & Hp1S-1S & $25(24.5 \%)^{\mathrm{a}, \mathrm{b}}$ & $8(14.5 \%)^{\mathrm{a}}$ & $9(15 \%)^{\mathrm{a}}$ & $\leq 0.001^{*}$ \\
\hline & Hp1F-1F & $6(5.9 \%)^{\mathrm{a}, \mathrm{b}, \mathrm{c}}$ & $6(10.9 \%)^{a}$ & $9(15 \%)^{\mathrm{a}}$ & \\
\hline & Hp1S-1F & $1(1 \%)^{a, b, c}$ & $2(3.6 \%)^{\mathrm{a}}$ & $3(5 \%)^{\mathrm{a}}$ & \\
\hline & $\mathrm{Hp} 2-1 \mathrm{~S}$ & $11(10.8 \%)^{\mathrm{a}, \mathrm{c}}$ & $13(23.6 \%)^{\mathrm{a}}$ & $13(21.7 \%)^{\mathrm{a}}$ & \\
\hline & $\mathrm{Hp} 2-1 \mathrm{~F}$ & $4(3.9 \%)^{\mathrm{c}}$ & $10(18.2 \%)^{\mathrm{a}}$ & $10(16.7 \%)^{\mathrm{a}}$ & \\
\hline & Hp2-2 & $55(53.9 \%)^{\mathrm{a}, \mathrm{b}}$ & $16(29.1 \%)^{\mathrm{a}}$ & $16(26.7 \%)^{\mathrm{a}}$ & \\
\hline \multirow{3}{*}{$\mathrm{Hp}$ allele frequencies } & $\mathrm{Hp}^{1 \mathrm{~S}}$ & 0.304 & 0.282 & 0.283 & \\
\hline & $\mathrm{Hp}^{1 \mathrm{~F}}$ & 0.084 & 0.218 & 0.258 & \\
\hline & $\mathrm{Hp}^{2}$ & 0.613 & 0.5 & 0.458 & \\
\hline
\end{tabular}

$a, b$, and $c$ : values with different letters in the same line are significantly different at $p<0.05$; SD: standard deviation; $*$ : chi ${ }^{2}$ test with the Bonferroni adjustment and Fischer test for small size groups.

aged below 18 years. This could be explained by the early mortality of SCD patients. Indeed, according to Houwing et al. [32], more than half of SCD patients die before the age of 5 years in sub-Saharan Africa. These results are in agreement with those of Dahmani et al. [33] where the most affected age groups in SCP were children under 10 years of age.

The present study revealed that the most common $\mathrm{Hp}$ genotype in the population of West Cameroon is Hp2-2 (40\%), followed by Hp1-1 (32\%) and Hp2-1 (28\%). This distribution is different from that obtained by Constans et al. [34] in a study which investigated protein polymorphisms in Pygmy Bi-Aka, a population of the east region of Cameroon. They obtained a majority of Hp2-1 (47\% against $41 \%$ for Hp2-2 and 12\% for Hp1-1). These results are also different from those obtained by Destro-Bisol et al. [35] which revealed a predominance of $\mathrm{Hpl}-1$ (56\%) against 5\% and
$39 \%$ for Hp2-2 and Hp2-1, respectively, in a study focused on serum genetic polymorphism among the Bakakas, a population of the littoral region of Cameroon. These differences could be explained by the ethnic and geographic segregation (west, east, and littoral regions of Cameroon). According to several authors, the polymorphic distribution of Hp varies according to the geographical area [6, 28-30]. Our present results confirm this geographical variability.

Anemia observed in SCP, expressed by low levels of $\mathrm{Hb}$ $(7.49 \mathrm{~g} / \mathrm{dL})$ and $\mathrm{RBC}\left(2.98 \times 10^{12} / \mathrm{L}\right)$, following the chronic hemolysis present on these patients. This could be explained by the rigidity of the sickle $\mathrm{RBC}$, which consequently has a reduced lifespan average, about 10 to 20 days instead of 120 days like normal RBC. Indeed, in case of deoxygenation, there is polymerization of $\mathrm{HbS}$ causing damage to the erythrocytes membrane that becomes rigid and fragile, thus leading to their hemolysis [32]. These results are in 
TABLE 6: Variation of hematological profile according to the Hp genotype in SS patients.

\begin{tabular}{|c|c|c|c|c|c|c|c|}
\hline Parameters & Hp 1S-1S & Hp 1F-1F & Hp 1S-1 F & Hp 2-1S & Hp 2-1F & Hp 2-2 & $p$ value \\
\hline Number of individuals & $25(24.5 \%)$ & $6(5.9 \%)$ & $1(1 \%)$ & $11(10.8 \%)$ & $4(3.9 \%)$ & $55(53.9 \%)$ & \\
\hline $\mathrm{Hb}(\mathrm{g} / \mathrm{dL})$ & $7.19 \pm 1.03$ & $8.23 \pm 2.62$ & 8.90 & $7.54 \pm 1.33$ & $7.62 \pm 0.70$ & $7.49 \pm 1.30$ & 0.532 \\
\hline WBC $\left(\times 10^{9} / \mathrm{L}\right)$ & $17.12 \pm 6.24$ & $16.95 \pm 4.47$ & 11.90 & $20.89 \pm 13.28$ & $15.22 \pm 4.74$ & $18.33 \pm 8.82$ & 0.764 \\
\hline $\operatorname{RBC}\left(\times 10^{12} / \mathrm{L}\right)$ & $2.94 \pm 0.75$ & $3.42 \pm 1.25$ & 3.20 & $3.02 \pm 0.56$ & $2.97 \pm 0.48$ & $2.94 \pm 0.62$ & 0.737 \\
\hline Lymph $\left(\times 10^{9} / \mathrm{L}\right)$ & $8.42 \pm 4.26$ & $8.51 \pm 2.91$ & 6.50 & $7.43 \pm 1.74$ & $6.17 \pm 1.95$ & $8.76 \pm 5.56$ & 0.877 \\
\hline Mon $\left(\times 10^{9} / \mathrm{L}\right)$ & $1.76 \pm 0.76$ & $1.66 \pm 0.85$ & 1.10 & $1.93 \pm 0.70$ & $1.45 \pm 0.47$ & $2.01 \pm 0.94$ & 0.570 \\
\hline $\operatorname{Gran}\left(\times 10^{9} / \mathrm{L}\right)$ & $6.92 \pm 2.71$ & $6.76 \pm 1.71$ & 4.30 & $11.51 \pm 12.46$ & $7.60 \pm 4.04$ & $7.55 \pm 3.79$ & 0.223 \\
\hline Lymph\% & $48.5 \pm 10.4$ & $49.4 \pm 8.2$ & 54.6 & $40.6 \pm 11.9$ & $41.9 \pm 15.2$ & $46.5 \pm 10.0$ & 0.300 \\
\hline Mon\% & $10.7 \pm 3.8$ & $9.6 \pm 2.7$ & 9.0 & $10.4 \pm 3.9$ & $9.5 \pm 1.5$ & $11.5 \pm 3.5$ & 0.659 \\
\hline Gran\% & $40.8 \pm 9.7$ & $41.0 \pm 8.6$ & 36.4 & $49.0 \pm 13.3$ & $48.6 \pm 16.0$ & $42.0 \pm 10.3$ & 0.269 \\
\hline HCT (\%) & $26.33 \pm 5.58$ & $29.43 \pm 7.97$ & 30.60 & $26.81 \pm 5.08$ & $27.95 \pm 3.05$ & $26.99 \pm 4.75$ & 0.798 \\
\hline MCV (fL) & $91.25 \pm 11.17$ & $88.50 \pm 9.53$ & 95.90 & $89.13 \pm 7.20$ & $94.95 \pm 8.50$ & $91.29 \pm 15.25$ & 0.965 \\
\hline $\mathrm{MCHC}(\mathrm{g} / \mathrm{dL})$ & $28.30 \pm 1.72$ & $27.73 \pm 3.21$ & 29.0 & $28.18 \pm 1.23$ & $27.30 \pm 1.02$ & $27.70 \pm 1.22$ & 0.586 \\
\hline $\operatorname{PLT}\left(\times 10^{9} / \mathrm{L}\right)$ & $458 \pm 175$ & $451 \pm 307$ & 551 & $454 \pm 202$ & $608 \pm 169$ & $463 \pm 166$ & 0.733 \\
\hline MPV (fL) & $9.92 \pm 0.63$ & $9.91 \pm 0.50$ & 9.20 & $10.03 \pm 0.56$ & $9.75 \pm 0.50$ & $9.76 \pm 0.75$ & 0.720 \\
\hline $\mathrm{MCH}(\mathrm{pg})$ & $25.85 \pm 3.85$ & $24.36 \pm 2.79$ & 27.80 & $25.03 \pm 2.21$ & $25.85 \pm 2.37$ & $25.77 \pm 9.96$ & 0.828 \\
\hline RDW-CV\% & $23.4 \pm 3.2$ & $22.7 \pm 5.6$ & 19.0 & $23.3 \pm 2.9$ & $22.2 \pm 1.2$ & $23.8 \pm 3.5$ & 0.727 \\
\hline RDW-SD (fL) & $75.6 \pm 14.8$ & $73.1 \pm 20.7$ & 66.1 & $74.4 \pm 8.3$ & $74.3 \pm 9.2$ & $78.0 \pm 13.4$ & 0.837 \\
\hline PDW & $14.7 \pm 0.4$ & $14.6 \pm 0.2$ & 14.1 & $14.7 \pm 0.2$ & $14.6 \pm 0.2$ & $14.7 \pm 0.4$ & 0.591 \\
\hline РСТ\% & $0.42 \pm 0.10$ & $0.37 \pm 0.24$ & 0.51 & $0.39 \pm 0.08$ & $0.47 \pm 0.19$ & $0.43 \pm 0.14$ & 0.809 \\
\hline
\end{tabular}

WBC: white blood cells; RDW: red cell distribution width; PDW: platelet distribution width; PCT: platelet crit; ANOVA test.

TABLE 7: Some manifestations of the severity of SCD according to the Hp genotype in SS patients.

\begin{tabular}{|c|c|c|c|c|c|c|c|c|}
\hline Parameters & & Hp 1S-1S & Hp 1F-1 F & Hp 1S-1 F & Hp 2-1S & Hp 2-1F & Hp 2-2 & $p$ value \\
\hline \multirow{3}{*}{ VOC } & 0 & $5(20.8 \%)$ & $0(0.0 \%)$ & $0(0.0 \%)$ & $1(9.1 \%)$ & $0(0.0 \%)$ & $4(7.7 \%)$ & $0.353^{\phi}$ \\
\hline & $1-2$ & $10(41.7 \%)$ & $1(16.7 \%)$ & $1(100 \%)$ & $3(27.3 \%)$ & $1(25 \%)$ & $25(48.1 \%)$ & \\
\hline & 3 and above & $9(37.5 \%)$ & $5(83.3 \%)$ & $0(0.0 \%)$ & $7(63.6 \%)$ & $3(75 \%)$ & $23(44.2 \%)$ & \\
\hline \multirow{3}{*}{ Hospitalization } & 0 & $8(33.3 \%)$ & $1(16.7 \%)$ & $0(0.0 \%)$ & $5(45.5 \%)$ & $1(25 \%)$ & $20(37.7 \%)$ & $0.756^{\phi}$ \\
\hline & 1 & $10(41.7 \%)$ & $2(33.3 \%)$ & $1(100 \%)$ & $5(45.5 \%)$ & $1(25 \%)$ & $19(35.8 \%)$ & \\
\hline & 2 and above & $6(25 \%)$ & $3(50 \%)$ & $0(0.0 \%)$ & $1(9.1 \%)$ & $2(50 \%)$ & $14(26.4 \%)$ & \\
\hline \multirow{2}{*}{ Transfusion } & 0 & $12(50 \%)$ & $4(66.7 \%)$ & $1(100 \%)$ & $8(72.7 \%)$ & $3(75 \%)$ & $29(54.7 \%)$ & $0.667^{\phi}$ \\
\hline & 1 and above & $12(50 \%)$ & $2(33.3 \%)$ & $0(0.0 \%)$ & $3(27.3 \%)$ & $1(25 \%)$ & $24(45.3 \%)$ & \\
\hline \multirow{2}{*}{ Anemia } & yes & $23(95.8 \%)$ & $4(66.7 \%)$ & $1(100 \%)$ & $11(100 \%)$ & $4(100 \%)$ & $53(96.4 \%)$ & $0.055^{\phi}$ \\
\hline & no & $1(4.2 \%)$ & $2(33.3 \%)$ & $0(0.0 \%)$ & $0(0 \%)$ & $0(0 \%)$ & $2(3.6 \%)$ & \\
\hline \multirow{3}{*}{ Anemia severity $^{a}$} & Severe & $11(47.8 \%)$ & $3(75 \%)$ & $0(0.0 \%)$ & $3(27.3 \%)$ & $1(25 \%)$ & $18(34 \%)$ & \\
\hline & Moderate & $11(47.8 \%)$ & $1(25 \%)$ & $1(100 \%)$ & $8(72.7 \%)$ & $3(75 \%)$ & $33(62.3 \%)$ & $0.803^{\phi}$ \\
\hline & Mild & $1(4.3 \%)$ & $0(0 \%)$ & $0(0.0 \%)$ & $0(0.0 \%)$ & $0(0.0 \%)$ & $2(3.7 \%)$ & \\
\hline \multirow{3}{*}{ Type of anemia ${ }^{b}$} & Macrocytic & $16(69.6 \%)$ & $2(50 \%)$ & $1(100 \%)$ & $5(45.5 \%)$ & $2(50 \%)$ & $29(55.8 \%)$ & \\
\hline & Normocytic & $6(26.1 \%)$ & $2(50 \%)$ & $0(0.0 \%)$ & $5(45.5 \%)$ & $2(50 \%)$ & $19(36.5 \%)$ & $0.948^{\phi}$ \\
\hline & Microcytic & $1(4.3 \%)$ & $0(0 \%)$ & $0(0.0 \%)$ & $1(9.0 \%)$ & $0(0.0 \%)$ & $4(7.7 \%)$ & \\
\hline \multirow{3}{*}{ Type of hyperleucocytosis ${ }^{c}$} & Moderate & $9(40.9 \%)$ & $2(33.3 \%)$ & $1(100 \%)$ & $3(27.3 \%)$ & $3(75 \%)$ & $20(40 \%)$ & \\
\hline & Plain & $6(27.3 \%)$ & $2(33.3 \%)$ & $0(0.0 \%)$ & $6(54.5 \%)$ & $0(0.0 \%)$ & $15(30 \%)$ & $0.711^{\phi}$ \\
\hline & Severe & $7(31.8 \%)$ & $2(33.3 \%)$ & $0(0.0 \%)$ & $2(18.2 \%)$ & $1(25 \%)$ & $15(30 \%)$ & \\
\hline \multirow{2}{*}{ CRP } & Negative & $17(73.9 \%)$ & $2(50 \%)$ & $1(100 \%)$ & $7(63.6 \%)$ & $1(25 \%)$ & $18(39.1 \%)$ & $0.071^{\phi}$ \\
\hline & Positive & $6(26.1 \%)$ & $2(50 \%)$ & $0(0.0 \%)$ & $4(36.4 \%)$ & $3(75 \%)$ & $28(60.9 \%)$ & \\
\hline BMI $\left(\mathrm{m} / \mathrm{kg}^{2}\right)$ & & $16.60 \pm 2.70$ & $17.13 \pm 3.67$ & 14.0 & $16.99 \pm 1.60$ & $14.90 \pm 0.57$ & $17.14 \pm 2.82$ & $0.550^{\alpha}$ \\
\hline
\end{tabular}

VOC: number of vaso-occlusive crisis (VOC) in one year; hospitalization: number of hospitalizations in one year; transfusion: number of sanguine transfusions in one year; a: severe anemia: $\mathrm{Hb}<7 \mathrm{~g} / \mathrm{dL}$, moderated anemia: $7 \mathrm{~g} / \mathrm{dL} \leq \mathrm{Hb}<9 \mathrm{~g} / \mathrm{dL}$, mild anemia: $9 \mathrm{~g} / \mathrm{dL} \leq \mathrm{Hb}<11 \mathrm{~g} / \mathrm{dL}$; b: macrocytic anemia: MCV > $90 \mathrm{fL}$, normocytic anemia: $80 \mathrm{fL} \leq \mathrm{MCV} \leq 90 \mathrm{fL}$, microcytic anemia: MCV $<80 \mathrm{fL}$; c: moderate hyperleucocytosis: $10 \times 109 / \mathrm{L}<\mathrm{WBC}>15 \times 10$ 9/L, plain hyperleucocytosis: $15 \times 109 / \mathrm{L} \leq \mathrm{WBC} \geq 20 \times 109 / \mathrm{L}$, severe hyperleucocytosis: WBC > $20 \times 109 / \mathrm{L}$; CRP: C-rective protein; BMI: body mass index; $\phi$ : chi2 test with the Bonferroni adjustment and Fischer test; $\alpha$ : ANOVA test.

agreement with those of Tshilolo et al. [36] in Democratic Republic of Congo (RDC) and Mick et al. [37] in RDC and Dahmani et al. [33] in Morocco, which showed significantly low levels of $\mathrm{Hb}$ and $\mathrm{RBC}$ in SS patients compared to controls.
The current study is the first to show the Hp genotype distribution among SCP in Cameroon. It revealed that the Hp2-2 genotype is significantly more represented in sickle cell patients (54\%), while in AS and AA, Hp2-1 is significantly more represented ( $42 \%$ and $38 \%$, respectively). For 
the allele frequency distribution, $\mathrm{Hp}^{2}$ is the most frequent in SS patients (0.62). These results are similar to those obtained by Adelike and Haider [6] in Kuwaiti patients. Their research showed that the most frequent genotypes were Hp2-2 (52\%) in SS patients and Hp2-1 (49\%) in AA controls, and the frequency of $\mathrm{Hp}^{2}$ allele in SS patients was 0.74 . However, these are different from those of Olatunya et al. [38] in Nigeria, Khalid and Khalil [39] in Sudan, Moreira and Naoum [24] in Brazil, and Ostrowski et al. [23] in USA, where the most frequent $\mathrm{Hp}$ genotype in SS patients was Hp1-1 (43\%, 68\%, 36\%, and 72\%, respectively). Furthermore, the previous work of Bruna et al. [40] in Brazil showed Hp2-1 as the most frequent $\mathrm{Hp}$ genotype in SS patients (57\%). This multiplicity and the variability of results highlight the need for more studies among many cohorts with diverse ethnic backgrounds to provide more understanding on the Hp polymorphism distribution in SS patients. Since a large body of evidence suggests that the $\mathrm{Hp}^{2}$ allele is a major susceptibility gene for (i) the development of vascular complications such as coronary artery and cardiovascular disease [41], (ii) the development of oxidative stress [21], and (iii) for inflammatory status [20], SS patients with the Hp2-2 genotype require enhanced attention and specific healthcare management.

This study also allowed us to examine the association of the Hp polymorphism with frequent vaso-occlusive crisis (VOC), hospitalization, transfusion, and hematological parameters. No significant difference has been found between these parameters according to $\mathrm{Hp}$ genotypes. Regarding the frequencies of VOC, these results are similar to those of Adelike and Haider [6] who observed no significant difference in the frequencies of the $\mathrm{Hp}$ alleles and no significant association of the $\mathrm{Hp}^{2}$ allele with increased VOC frequency in Kuwaiti SS patients. Concerning the hematological profile, the results obtained from the present study corroborate those of Bruna et al. [40], Khalid and Khalil [39], and Olatunya et al. [38] who did not find any significant difference between hematological profiles regarding Hp genotypes. Nevertheless, Gueye et al. [26] in Senegal found that SS patients with the Hp2-2 genotype exhibited significantly lower $\mathrm{Hb}$ means compared to Hp1-1 and Hp2-1 subjects. They justified their results by explaining that the Hp2-2 genotype was less effective in binding $\mathrm{Hb}$ and neutralizing its oxidative power. Therefore, the patients with Hp2-2 would be more predisposed to severe anemia compared to subjects with other genotypes. Despite the latter, they also indicated that their results should be interpreted with caution, especially by taking into consideration factors such as the $\mathrm{HbF}$ level, which could interfere in the modulation of the severity of anemia [26].

Despite the lack of influence of other genotypes on the hematological parameters, SCPs with the Hp1S-1F genotype presented the highest levels of hemoglobin, albeit from only 1 result. Because of the small size of the Hp1S-1F genotype, we cannot make a conclusion about a protective effect of the Hp1S-1F genotype. One limitation of the current study could be the small-size sample. A larger sample size could have more power and could probably yield more associations with certain parameters among SCP.

\section{Conclusions}

Our study describes the Hp genotype distribution among sickle cell patients in Cameroon. It reveals that the Hp2-2 genotype is the most represented one in SS patients in West Cameroon. This work did not reveal any significant association between the haptoglobin gene polymorphism and the hematological parameters, as well as some severity manifestations of the disease; however, SCP with the Hp1S-1F genotype presented the highest level of hemoglobin. These results suggest that the polymorphism of the haptoglobin gene may not be a major genetic contributor of sickle cell anemia severity. More prospective studies need to be conducted to explore Hp polymorphism and several other SCA manifestations in sickle cell patients in Cameroon.

\section{Data Availability}

Data can be obtained from the corresponding author.

\section{Ethical Approval}

This study was approved by the Ethics Review and Consultancy Committee (ERCC) of CAMBIN (Cameroon Bioethics Initiative) with reference no: CBI/424/ERCC/ CAMBIN.

\section{Consent}

Written informed consent of participants/parents/caregivers was obtained.

\section{Conflicts of Interest}

The authors declare no conflicts of interest regarding the publication of this paper.

\section{Authors' Contributions}

CBKF led the study, performed laboratory and statistical analyses and literature review, and wrote the manuscript. PBN conceived the research project, reviewed the statistical analyses and manuscript, and jointly directed the study. SA and JPC contributed to the work material availability, data collection, and laboratory analyses. GT and CN contributed to the work material availability. GN and JTN contributed to sample and data collection. WFM and CAP jointly directed the work, and DG supervised the study. All authors contributed to the drafting of the manuscript.

\section{Acknowledgments}

The authors thank Mr. KEPTCHEU Désiré and the staff of the laboratory of Bafoussam Regional Hospital for their 
advices and practical support during the sample collection. They also thank Mr. TAH Calvino and Mr NANA William of the Laboratory for Public Health Research Biotechnology of Nkolbisson for their help during Hp genotyping.

\section{References}

[1] L. Tshilolo, M. N. Zita, R. Ngiyulu, and D. Kayembe Nzongola, "Iron status in 72 Congolese patients with sickle cell anemia," Médecine et Santé Tropicales, vol. 26, no. 1, pp. 83-87, 2016.

[2] A. Wonkam, V. J. Ngo Bitoungui, and J. Ngogang, "Perspectives in genetics and sickle cell disease prevention in Africa: beyond the preliminary data from Cameroon," Public Health Genomics, vol. 18, no. 4, pp. 237-241, 2015.

[3] WHO, Drépanocytose: Une stratégie pour la région africaine de L'OMS. Rapport du Directeur du Comité Régional de l'Afrique, Soixantième session Malabo, Guinée équatoriale, WHO, Geneva, Switzerland, 2010.

[4] S. Behera, S. Dixit, G. Bulliyya, and S. K. Kar, "Vitamin A status and hematological values in sickle cell disorder cases," Indian Journal of Medical Sciences, vol. 66, no. 7, pp. 169-174, 2012.

[5] M. G. Frances, A. S. Lynn, J. W. Steven, K. B. Audrey, B. Rita, and G. Ranjeet, "Clinical events in the first decade in a cohort of infants with sickle cell disease," Blood, vol. 86, no. 2, pp. 776-783, 1995.

[6] A. D. Adekile and M. Z. Haider, "Haptoglobin gene polymorphisms in sickle cell disease patients with different $\beta \mathrm{s}-$ globin gene haplotypes," Medical Principles and Practice, vol. 19, no. 6, pp. 447-450, 2010.

[7] D. J. Schaer, P. W. Buehler, A. I. Alayash, J. D. Belcher, and G. M. Vercellotti, "Hemolysis and free hemoglobin revisited: exploring hemoglobin and hemin scavengers as a novel class of therapeutic proteins," Blood, vol. 121, no. 8, pp. 1276-1284, 2013.

[8] K. R. Quimby, I. R. Hambleton, and R. C. Landis, "Intravenous infusion of haptoglobin for the prevention of adverse clinical outcome in Sickle Cell Disease," Medical Hypotheses, vol. 85, no. 4, pp. 424-432, 2015.

[9] J. A. Graw, B. Yu, E. Rezoagli, H. S. Warren, E. S. Buys, and D. B. Bloch, "Endothelial dysfunction inhibits the ability of haptoglobin to prevent hemoglobin-induced hypertension," American Journal of Physiology - Heart and Circulatory Physiology, .

[10] V. Bamm, A. Geist, and G. Harauz, "Correlation of geographic distributions of haptoglobin alleles with prevalence of multiple sclerosis (MS) - a narrative literature review," Metabolic Brain Disease, vol. 32, pp. 19-34, 2017.

[11] I. Hochberg, E. M. Berinstein, U. Milman, C. Shapira, and A. P. Levy, "Interaction between the haptoglobin genotype and vitamin E on cardiovascular disease in diabetes," Current Diabetes Reports, vol. 17, no. 42, pp. 1-6, 2017.

[12] M. N. Santos, M. A. Bezerra, B. L. Domingues et al., "Haptoglobin genotypes in sickle-cell disease," Genetic Testing and Molecular Biomarkers, vol. 15, no. 10, pp. 709-713, 2011.

[13] M. Langlois and J. Delanghe, "Biological and clinical significance of haptoglobin polymorphism in humans," Clinical Chemistry, vol. 42, no. 10, pp. 1589-1600, 1996.

[14] M.-F. Jayle and O. Judas, "Formule glycoprotéidique du plasma sanguin," Helvetica Chimica Acta, vol. 29, pp. 13101314, 1946.

[15] O. Smithies, "Zone electrophoresis in starch gels: group variation in the serum proteins of normal human adults," Biochemical Journal, vol. 61, pp. 629-641, 1955.
[16] O. Smithies and N. F. Walker, "Notation for serum-protein groups and the genes controlling their inheritance," Nature, vol. 178, pp. 694-695, 1956.

[17] G. E. Connell, G. H. Dixon, and O. Smithies, "Subdivision of the three common haptoglobin types based on 'hidden' differences," Nature, vol. 193, pp. 505-506, 1962.

[18] O. Smithies, G. E. Connell, and G. H. Dixon, "Inheritance of haptoglobin subtypes," The American Journal of Human Genetics, vol. 14, pp. 14-21, 1962.

[19] A. Yano, Y. Yamamoto, M. Saturo, and I. Hideo, "Haptoglobin genotyping by allele-specific polymerase chain reaction amplification," Acta Medica Okayama, vol. 52, no. 4, pp. 173-181, 1998.

[20] V. Van, M. Langlois, and J. Delanghe, "Haptoglobin polymorphisms and iron homeostasis in health and in disease," Clinica Chimica Acta, vol. 345, pp. 35-42, 2004.

[21] M. Melamed-Frank, O. Lache, B. Enav et al., "Structurefunction analysis of the antioxidant properties of haptoglobin," Blood, vol. 98, no. 13, pp. 3693-3698, 2001.

[22] A. Roguin, I. Hochberg, E. Nikolsky et al., "Haptoglobin phenotype as a predictor of restenosis after percutaneous transluminal coronary angioplasty," The American Journal of Cardiology, vol. 87, pp. 330-332, 2001.

[23] R. Ostrowski, J. Travis, and E. Talley, "The association of Hp 1 and sickle cell disease," Human Heredity, vol. 37, pp. 193-195, 1987.

[24] H. Moreira and P. Naoum, "Serum haptoglobin types in patients with hemoglobinopathies," Hereditas, vol. 113, pp. 227-231, 1990.

[25] H. Hughes, F. Kutlar, B. Clair, D. Elam, K. M. McKie, and A. Kutlar, "Haptoglobin genotypes among pediatric and adult sickle cell patients: an emerging genetic modifier?" Blood, .

[26] P. Gueye, F. Gueye-Tall, M. Seck, M. Kane, R. Diallo, and M. Diatta, "Aggravation de l'anémie et polymorphisme de l'haptoglobine au cours de la drépanocytose au Sénégal," International Journal of Biological Chemical Science, vol. 8, no. 3, pp. 975-982, 2014.

[27] N. Chintagari, J. Nguyen, J. Belcher, G. Vercellotti, and A. Alayash, "Haptoglobin attenuates hemoglobin-induced heme oxygenase- 1 in renal proximal tubule cells and kidneys of a mouse model of sickle cell disease," Blood Cells Molecules and Diseases, .

[28] P. Khurana, A. Aggarwal, S. Huidrom, and G. Kshatriya, "Haptoglobin polymorphism among the tribal groups of southern Gujarat," Indian J Hum Genet Indian J Hum Genet, vol. 17, no. 3, pp. 169-175, 2011.

[29] K. Ratanasopa, C. Sandeep, I. Muhammad, N. Chanin, and B. Leif, "Trapping of human hemoglobin by haptoglobin: molecular mechanisms and clinical applications," Antioxidants and Redox Signaling, vol. 18, no. 13, pp. 2364-2374, 2013.

[30] C. Andersen, K. Stødkilde, K. Sæderup, A. Kuhlee, S. Raunser, and J. Graversen, Haptoglobin. Antioxid Redox Signal.vol. 26, no. 14, pp. 814-831, 2017.

[31] C. V. Plowe, A. Djimde, M. Bouare, O. Doumbo, and T. E. Wellems, "Pyrimethamine and proguanil resistanceconferring mutations in Plasmodium falciparum dihydrofolate reductase: polymerase chain reaction methods for surveillance in Africa," The American Journal of Tropical Medicine and Hygiene, vol. 52, no. 6, pp. 565-568, 1995 Jun.

[32] M. E. Houwing, P. J. De Pagter, E. J. Van Beers, B. J. Biemond, E. Rettenbacher, and A. W. Rijneveld, "Sickle cell disease: clinical presentation and management of a global health challenge," Blood Reviews, . 
[33] F. Dahmani, S. Benkirane, J. Kouzih, W. Aziz, M. Hassan, and A. Masrar, "Etude de l'hémogramme dans la drépanocytose homozygote: à propos de 87 patients. Pan," African Medical Journal, vol. 25, pp. 240-250, 2016.

[34] J. Contans, M. Viau, G. Jaeger, and M. J. Palisson, "Gc, tf, Hp subtype and $\alpha_{1}$-antitrypsin polymorphisms in a Pygmy Bi-aka sample," Human Heredity, vol. 31, pp. 129-137, 1981.

[35] G. Destro-Bisol, C. Battaggia, R. Macchiarelli, C. Bailey, M. R. Scozzari, and G. Spedini, "A bio-anthropological study on the Bakakas of Cameroon," Annals of Human Biology, vol. 19, no. 2, pp. 185-195, 1992.

[36] L. Tshilolo, M. N. Zita, R. Ngiyulu, and D. Kayembe Nzongola, "Le statut martial chez soixante-douze drépanocytaires homozygotes congolais," Tropical Medicine and Health, vol. 26, pp. 83-87, 2016.

[37] Y. P. Mick, M. Olivier, M. M. Augustin, K. L. Toni, M. I. Paul, and U. S. Winnie, "Profil hématologique et nutritionnel du drépanocytaire homozygote SS âgé de 6 à 59 mois à Lubumbashi, République Démocratique du Congo," The Pan African medical journal, vol. 21, pp. 276-282, 2015.

[38] O. S. Olatunya, M. A. Dulcineia, N. N. Magnun, S. K. Tolorunju, A. Adekunle, and F. C. Fernando, "Haptoglobin gene polymorphism in patients with sickle cell anemia: findings from a Nigerian cohort study," The Application of Clinical Genetics, vol. 13, pp. 107-114, 2020.

[39] H. O. Khalid and H. B. Khalil, "Haptoglobin Phenotypes distribution among Sickle Cell anaemia patients with different genotypes," European Academic Research, vol. 3, no. 6, pp. 6587-6598, 2015.

[40] S. Bruna, V. Perla, S. M. Sandra, A. A. Samuel, M. Grazielle, and S. F. Maria, "Haptoglobin gene polymorphisms and interleukin-6 and -8 levels in patients with sickle cell anaemia," Revista Brasileira de Hematologia e Hemoterapia, vol. 37, no. 5, pp. 329-335, 2015.

[41] H. C. Brown, F. Kutlar, C. Betsy, and K. Abdullah, "Exploratory study of haptoglobin levels by genotype in adult sickle cell patients," Blood, vol. 118, 2011. 